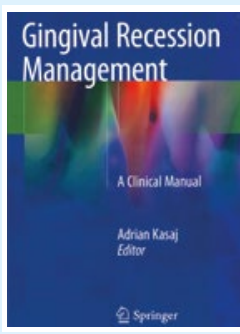

\section{GINGIVAL RECESSION MANAGEMENT. A} CLINICAL MANUAL

Adrian Kasaj

2018; Springer

price $€ 123.00$ pp. 157

ISBN: 9783319707174

This book aims to serve as a clinical manual for gingival recession management. The main focus is on the surgical techniques used for recession coverage using either soft tissue substitutes or autogenous tissues. Written by leading academics and specialists, the book is predominantly aimed at specialist periodontists or those practitioners with a specialist interest in the subject.

This hardback book consists of 11 concise chapters which are organised in a logical fashion. Each chapter starts with an abstract giving an informative overview. They are then further divided through the use of subheadings. The first three chapters focus on defining gingival recession and its classification and a review of local anatomy.
The aetiology and prevalence of gingival recession are also explored. Clinical examination and diagnostics then follow, along with the non-surgical management of gingival recession. The book then moves on to the basic principles of periodontal plastic surgery and surgical decision-making. Recession coverage using autogenous grafts and soft tissue substitutes are then reviewed. Finally, complications and surgical aftercare are discussed.

What really stood out is the quality of the step-by-step photographs of the procedures shown. These, along with clear schematic drawings, really help the reader grasp the techniques to facilitate their replication in practice. Relevant papers are referenced throughout the guide and detailed at the end of each chapter should the reader want a better understanding of the literature underpinning the subject.

The book is very informative and more importantly easy to follow. It is surgically orientated and gives you an overall understanding of the subject; it would be excellent as an adjunct to those in postgraduate training. Overall, this book definitely meets the aim of acting as a concise clinical manual on gingival recession management.

Omar Alimazighi

\title{
FOCUS ON the British Association of Oral and Maxillofacial Surgery (BAOMS)
}

\section{D-Day fundraising}

A commemorative parachute drop took place on 6 June on the 75th anniversary of D-Day, to raise essential funds for the National Facial, Oral and Oculoplastic Research Centre (NFORC), funded by research charity Saving Faces and partner the British Association of Oral and Maxillofacial Surgery (BAOMS). The drop took place near Caen in Normandy on D-Day (6 June) and another will take place near Arnhem in the Netherlands on 17 September. As in 1944 the jumps will take place from Dakota aircraft.

Ex-paratrooper Frank Fletcher is making the parachute jumps to raise money for Saving Faces and for Special Forces veterans' charity Pilgrim Bandits. Frank said: 'I wanted to make the two jumps as a mark of respect for my former colleagues and to commemorate what they achieved. I have seen facial wounds as a result of conflict, and the work of maxillofacial surgeons and the support both charities give is amazing - and that's why it's important to raise awareness and money to continue the work they do'

\section{HPV jab for boys will save lives}

BAOMS has welcomed new findings from the two-year Cancer Research UK-funded study in Scotland that the HPV vaccination for boys may substantially reduce head and neck cancer.

BAOMS had been involved in successfully lobbying for the extension to the HPV to boys last year in England and Northern Ireland. Typically, life-threatening HPV-related cancers can develop during middle age, but boys had been excluded from the national HPV vaccination programme. Since the UK-wide immunisation scheme for girls aged 12 and 13 was introduced in 2008, data show a reduction of up to $90 \%$ of pre-cancerous cells in the smear tests among women aged 20 .
BAOMS Chair Patrick Magennis explained that the cost of treating just HPV-driven mouth and throat cancer to the NHS is approximately $\mathfrak{E 3 0}$ million a year: 'Between 2010 and 2012 nearly 2,000 men had HPV-related head and neck cancer. Over half of these oropharyngeal cancers are caused by HPV, and in the last decade alone the incidence of these cancers has doubled in the UK population.'

He welcomed the publication of the new study, which found that over two years in 235 male patients in Scotland with head and neck cancer, HPV was present in $60 \%$ of cases. The findings follow an earlier report, which suggested routine vaccination of schoolgirls in Scotland with HPV had led to a dramatic reduction in cervical disease in later life.

'Current evidence suggests that vaccination of boys in their teenage years will prevent them from developing HPV-related cancers in middle age. The introduction of male vaccination is timely, said Dr Magennis.

\section{BAOMS Conference}

BAOMS hosted a major three-day scientific conference in Birmingham from 3-5 July 2019, in conjunction with the American Association of Oral and Maxillofacial Surgeons (AAOMS).

The event debated controversies from diversity issues in surgery to the latest surgical practices and their place in today's NHS, and address how to unlock the talents and aspirations of trainee surgeons. A well-known advocate for women and girls' education was set to motivate women maxillofacial surgeons in the opening Norman Rowe lecture. Former $\mathrm{BBC}$ reporter and MP Martin Bell spoke about the expertise and skills of maxillofacial surgeons from his personal experience when he broke major facial bones in a fall. Well-known breast surgeon and patient advocate Dr Liz O'Riordan describedwhat it is like to be on the other side of the operating table. A post-event report will be included in a future issue of the $B D J$. 